\title{
RepresentaÇão política e a defensoria pública do Paraná
}

\author{
Political representation and the public defender's office of \\ Paraná
}

\begin{abstract}
Ana Zaiczuk Raggio
Graduada em Direito pelo Centro Universitário Curitiba, Pós-Graduanda em Direito Constitucional pela Academia Brasileira de Direito Constitucional, Estagiária de Pós-Graduação em Direito no Centro de Apoio Operacional das Promotorias de Justiça de Proteção aos Direitos Humanos - Área de Direitos Constitucionais - do Ministério Público do Paraná. E-mail: anazraggio@gmail.com.
\end{abstract}

RECEBIDO EM: 31.07 .2013

APROVADO EM: 04.01.2014

\section{RESUMO}

A Defensoria Pública foi prevista no ordenamento jurídico brasileiro pela Constituição da República de 1988, com a função de prestar assistência jurídica para população que não possui condições de contratar advogado. O órgão deveria ser estruturado por Lei Complementar de iniciativa do Chefe do Poder Executivo. Entretanto, no Estado do Paraná tal Lei foi sancionada somente em 2011, ou seja, com 23 anos de atraso. Analisando este caso, o presente trabalho pretende demonstrar que a tardia implementação da Defensoria Pública do Paraná está a demonstrar a existência de limitação na representação política dos interesses da população de baixa renda, com base em entrevistas e autores da teoria política.

Palavras-chave: Defensoria pública do Paraná. RepresentaÇão política. RepreSENTATIVIDADE DA POPULAÇÃO DE BAIXA RENDA.

\section{AbSTRaCT}

The Public Defender's office was forseen in the brazilian legal system by the Constitution of 1988 with the task of providing legal assistance to the population that cannot afford to hire a lawyer. The institution should be structured by law 
through the initiative of the Chief of the Executive. However, in the State of Paraná this law was enacted only in 2011, which means with 23 years of delay. Analyzing this case, this paper argues that the late implementation of the Public Defender's office of Paraná demonstrates the existence of limitations on the political representation of the interests of people with low income, based on interviews and authors of political theory.

Keywords: Public defender's office of Paraná. Political representation. RepreSENTATION OF INTERESTS OF PEOPLE WITH LOW INCOME.

SumáRIo: Introdução. 1. A defensoria pública como expressão dos interesses populares. 2. A implementação da defensoria pública do Paraná. 3. A Demora na implementação da defensoria pública do Paraná como limite de representação política. Conclusão. Referências.

\section{INTRODUÇÃo}

O primeiro dispositivo a tratar de participação política na Constituição de 1988 é o parágrafo único do artigo $1^{\circ}$ que prevê: "todo poder emana do povo, que o exerce por meio de representantes eleitos ou diretamente, nos termos desta Constituição".

Apesar de dispor expressamente que o poder é de titularidade do povo, sendo a vontade deste a que deveria ser expressada na atuação política dos representantes eleitos, de maneira a formar políticas públicas, bem como o ordenamento jurídico como um todo, entende-se que não é esta a realidade atual.

Os representantes políticos no Brasil são escolhidos em eleições livres por meio do voto universal, direto e secreto. Ou seja, os representantes são formalmente legitimados pelo povo. No entanto, sua atuação não corresponde, acredita-se, aos anseios populares, não estando, se poderia dizer, materialmente legitimados. As políticas públicas e o Direito em si, não servem ao povo em toda a sua extensão.

Há que se ressalvar que uma camada da população tem seus interesses positivados e perseguidos pelos representantes. Entretanto, para outras camadas, acredita-se que esta representação efetiva encontra limitações, primeiramente, de ordem econômica. As classes economicamente mais abastadas parecem possuir maior acesso aos representantes políticos, conquistando a persecução de suas demandas. Acredita-se que um dos motivos principais para este fenômeno seja a possibilidade de financiamento que esta classe oferece.

Este trabalho, portanto, busca demonstrar que os interesses da população de baixa renda se encontram fora do espectro de atuação dos representantes polí- 
ticos. Para tanto, irá se tratar da tardia implementação da Defensoria Pública do Estado do Paraná. Isto pois se entende que a demora para estruturação do órgão está a demonstrar um limite da representação política, visto que é essencialmente destinado à referida população.

A iniciativa para a criação da Defensoria Pública, seja em âmbito federal, como estadual, é do chefe do poder executivo, conforme expressão do artigo 61, § 1, II, "d", da Constituição de 1988 e, no caso do Estado do Paraná, do artigo 66, III da Constituição estadual. Destes artigos se extrai que tal iniciativa é privativa e, portanto, apenas Presidente da República e Governador do Estado podem apresentar o projeto de lei ao legislativo para estruturação do órgão.

A fim de aprofundar a presente proposição, realizaram-se 6 entrevistas $^{1}$ com pessoas que de alguma forma estiveram ligadas ao processo de implementação da Defensoria Pública do Paraná, com 5 perguntas abertas, semi-estruturadas e qualitativas sobre a perspectiva política que permeou o processo. Com as respostas, pretende-se complementar com dados empíricos da realidade paranaense as teorias sobre representação política.

\section{A deFENSORIA PÚbliCA COMO EXPRESSÃo dOS INTERESSES POPUlARES}

A Constituição da República de 1988 criou no ordenamento jurídico brasileiro a Defensoria Pública no artigo 134, in verbis:

Art. 134. A Defensoria Pública é instituição essencial à função jurisdicional do Estado, incumbindo-lhe a orientação jurídica e a defesa, em todos os graus, dos necessitados, na forma do art. $5^{\circ}$, LXXIV (sem destaque no original).

\footnotetext{
1 Foram entrevistadas a Professora assistente de Direito Penal da UFPR e PUC/PR, e advogada criminalista, Priscilla Placha Sá, responsável pela convocação da reunião que deu origem ao movimento "Defensoria Já"; Miguel Gualano de Godoy, Doutorando em Direito e pesquisador do Conselho Nacional de Desenvolvimento Científico e Tecnológico (CNPQ) na UFPR, que coordenou o processo de elaboração da Lei Orgânica da Defensoria Pública do Paraná como assessor jurídico da Secretaria de Estado da Justiça, Cidadania e Direitos Humanos do Paraná; Carlos Frederico Marés de Souza Filho, Professor titular da graduação e mestrado em Direito da PUC/PR, eminente atuante na área de Direito Socioambiental; Tadeu Veneri, Deputado estadual do Paraná em seu terceiro mandato pelo Partido dos Trabalhadores (PT), Presidente da Comissão de Direitos Humanos da Assembleia Legislativa, que buscava a implementação do órgão desde 2002 e que durante o movimento "Defensoria Já" foi o único parlamentar a participar diretamente das articulações políticas; Carlos Enrique Santana, coordenador do Centro de Direitos Humanos de Londrina, coordenador estadual do Movimento Nacional pelos Direitos Humanos e conselheiro do Conselho Municipal de Saúde de Londrina, cuja militância pela Defensoria iniciou no ano 2000; Maria Tereza Uille Gomes, Secretária de Estado da Justiça Cidadania e Direitos Humanos e ex Procuradorageral de Justiça do Estado do Paraná, que teve papel articulador entre a sociedade civil e o Poder Público.
} 
O artigo $5^{\circ}$, LXXIV determina, por sua vez, que "o Estado prestará assistência jurídica integral e gratuita destinada aos que comprovarem insuficiência de recursos". Portanto, a implementação da Defensoria Pública se mostra como expressão dos interesses das camadas menos abastadas, tendo em vista sua função de fornecer amparo jurídico àqueles que não possuem condições de contratar advogado.

Para levar uma demanda ao Poder Judiciário se faz necessário possuir capacidade postulatória. Entretanto a legislação brasileira determina que afora o Ministério Público e a Defensoria Pública, conforme se depreende da leitura dos artigos 127 e 134 da Constituição Federal, apenas o advogado possui esta capacidade de levar os interesses de um cidadão a conhecimento do Judiciário, pelo expresso no artigo 36 do Código de Processo Civil, in verbis:

Art. 36. A parte será representada em juízo por advogado legalmente habilitado. Ser-lhe-á lícito, no entanto, postular em causa própria, quando tiver habilitação legal ou, não a tendo, no caso de falta de advogado no lugar ou recusa ou impedimento dos que houver.

Assim sendo, o cidadão só poderá pleitear em sua própria defesa nas situações trazidas pelo artigo, ou ainda nas exceções legalmente previstas, quais sejam na impetração de habeas corpus (artigo 654 do Código de Processo Penal) e nas ações perante o Juizado Especial Cível (artigo $9^{\circ}$ da Lei no 9.099/95) e na Justiça do Trabalho (artigo 791 da Consolidação das Leis do Trabalho).

A inexistência de Defensoria Pública, dessa forma, impede o acesso à Justiça daqueles que não possuem condições econômicas de contratar um advogado. O que se mostra como flagrante violação do Estado Democrático de Direito e dos Direitos Fundamentais de inafastabilidade do Poder Judiciário, contraditório e ampla defesa e assistência jurídica gratuita, positivados no artigo $5^{\circ}$, incisos XXXV, LV e LXXIV, respectivamente, da Constituição de 1988.

Em um Estado Democrático de Direito, em que a justiça privada é vedada, sendo majoritariamente papel do ente público garantir a solução dos conflitos, alcançar o Poder Judiciário é essencial à cidadania, até mesmo para demandar o próprio poder público incumbido da prestação dos direitos sociais e do respeito aos direitos humanos. Demandas como requisição de fornecimento de remédios para tratamentos continuados ficam desprotegidas, não sendo levadas ao conhecimento dos poderes constituídos, a título de exemplo.

Grande impacto se dá também quando da falta de defesa em processos criminais. Enquanto a acusação é elaborada na maioria dos casos pela forte estrutura do Ministério Público, a população de baixa renda lota as cadeias e penitenciárias por não possuir quem alegue sua inocência e acompanhe a progressão de regime.

Portanto, a ausência de Defensoria Pública causa enormes impactos na não 
resolução de conflitos privados, na não garantia de direitos sociais e ainda sobrecarrega o sistema prisional brasileiro, dentre outras implicações.

A legislação brasileira previu, vezes antes, a obrigatoriedade estatal de proporcionar atendimento jurídico àqueles que não possuíam meios para contratar o serviço. Em 1950 foi promulgada a Lei de Assistência Judiciária, Lei no 1060/50, sendo recebida pela ordem constitucional atual. Esta determina aos "poderes públicos, federal e estadual" o dever de conceder "assistência judiciária aos necessitados". O parágrafo único do artigo $2^{\circ}$, do mesmo diploma legal, traz o conceito jurídico de necessitados, utilizado até a atualidade.

Parágrafo único. - Considera-se necessitado, para os fins legais, todo aquele cuja situação econômica não lhe permita pagar as custas do processo e os honorários de advogado, sem prejuízo do sustento próprio ou da família.

A Constituição de 88, portanto, avança no momento em que cria no âmbito estatal órgão direcionado unicamente ao atendimento da população em situação de vulnerabilidade econômica, com autonomia funcional e administrativa desde a Emenda Constitucional n ${ }^{\circ} 45$ de 2004 . Ou seja, a Constituição dá forma institucional para a previsão da Lei 1060/50.

Dando o primeiro passo para a existência do órgão e cumprindo a determinação do parágrafo $1^{\circ}$ do artigo 134 , que impõe a organização da Defensoria por Lei Complementar (LC), foi editada a LC 80 de 1994, que organiza a Defensoria Pública da União, do Distrito Federal e dos Territórios e prescreve normas gerais para sua organização nos Estados. Ressalta-se o reconhecimento dado por esta Lei quanto à importância do órgão para a garantia do Estado Democrático de Direito instituído pela Constituição da República de 1988.

Art. $1^{\circ}$ A Defensoria Pública é instituição permanente, essencial à função jurisdicional do Estado, incumbindo-lhe, como expressão e instrumento do regime democrático, fundamentalmente, a orientação jurídica, a promoção dos direitos humanos e a defesa, em todos os graus, judicial e extrajudicial, dos direitos individuais e coletivos, de forma integral e gratuita, aos necessitados, assim considerados na forma do inciso LXXIV do art. $5^{\circ}$ da Constituição Federal. (Redação dada pela Lei Complementar $n^{0} 132$, de 2009, sem grifo no original).

No III Diagnóstico Defensoria Pública no Brasil, do Ministério da Justiça (2009), para fins de análise da situação das Defensorias no Brasil, utiliza-se como parâmetro para determinação do público-alvo do órgão a renda mensal média de até três salários mínimos. Não existe determinação legal delimitando a renda máxima daquele que pode ser atendido pela Defensoria Pública, cada órgão possui sua nor- 
mativa interna para delimitação de atendimento, podendo cada caso ser analisado concretamente. No entanto, utiliza-se este parâmetro por possibilitar maior diálogo com os dados levantados pelo IBGE e consequente facilidade de interlocução com outros estudos, conforme IPEA e ANADEP (2013).

Ainda que o limite remuneratório apontado não seja suficiente para constatar a real situação de vulnerabilidade individual, ou mesmo familiar, já abrange uma grande porcentagem da população brasileira, indicando um enorme contingente de potenciais usuários da Defensoria Pública. Das 161.990.266 pessoas de 10 anos ou mais de idade residentes em todo o país, 52,6\% possuem rendimento nominal mensal de até 3 salários mínimos (IBGE, 2010).

\section{A implementaÇão da defensoria pública do Paraná}

Apesar da previsão constitucional ser de 1988, apenas em 1994 o Presidente da República pelo Partido do Movimento Democrático Brasileiro (PMDB), Itamar Franco, sancionou a LC 80/94 que organizou a Defensoria Pública da União, Distrito Federal e Território e estabeleceu normas gerais para a organização das Defensorias Estaduais. Ou seja, o primeiro passo em âmbito nacional para implementação do órgão, foi dado somente 5 anos após sua criação pela Constituição de 88 .

No Estado do Paraná, o artigo 128 da Constituição Estadual, promulgada em 5 de outubro de 1989, determina a organização do órgão por lei complementar com observância a legislação federal sobre a matéria. No entanto, mesmo com ausência da legislação federal em 1991, nos últimos meses de mandato, o então Governador Álvaro Dias, pelo PMDB, sancionou a Lei Complementar Estadual n ${ }^{0} 55$ que instituiu a Defensoria Pública do Estado do Paraná.

$\mathrm{O}$ artigo $6^{\circ}$ da Lei impunha o prazo de 180 (cento e oitenta) dias para que o Executivo encaminhasse à Assembleia Legislativa mensagem sobre a estruturação da carreira de Defensor Público e demais disposições necessárias ao funcionamento do órgão. Seu sucessor, Roberto Requião, do mesmo partido, no entanto, não cumpriu a determinação.

A LC 80/94 é promulgada poucos meses antes de o Governador Roberto Requião deixar o cargo antes do fim de seu mandato, assumindo o Vice-Governador Mário Pereira, também do PMDB. O artigo 142 desta Lei também concedia cento e oitenta dias para que os Estados adaptassem a organização da Defensoria Pública aos preceitos da Lei Complementar, mas o Paraná não atendeu a determinação. Seguiram-se ao governo PMDB dois mandatos de Jaime Lerner, um pelo Partido Democrático Trabalhista (PDT) e outro pelo Partido da Frente Liberal (PFL).

Em 2003, Roberto Requião assume novamente o Governo do Estado e permanece por dois mandatos subsequentes até 2010 e nenhuma legislação estadual surge para estruturar o órgão. Pouco antes das eleições de 2010, Requião deixa o mandato e o Vice-Governador, Orlando Pessuti, novamente do mesmo partido, apre- 
senta à Assembleia Legislativa do Paraná (ALEP) o Projeto de Lei (PL) n 439/2010, a fim de estruturar a Defensoria Pública.

Porém, o PL não é votado antes do fim das atividades legislativas daquele ano e acaba por ser retirado de pauta no ano seguinte pelo Governador recém-eleito pelo Partido da Social Democracia Brasileira (PSDB), Carlos Alberto Richa.

Somente em 19 de maio de 2011 a Lei Orgânica da Defensoria Pública do Estado do Paraná (LC no 136/11) é sancionada por Richa. Com vinte e três anos de atraso em relação à Constituição da República, vinte anos em relação a Lei Complementar Estadual 55/91 e 17 anos depois da LC 80/94, é organizada a Defensoria Pública do Paraná, sendo o penúltimo Estado da Federação a ter Defensoria, antes apenas do Estado vizinho, Santa Catarina.

Os direitos da população de baixa renda de todo o Estado foram reiteradamente violados e sua defesa improvisada.

Em 2010, 58\% da população paranaense com 10 anos ou mais de idade possuía classe de rendimento nominal mensal de até 3 salários mínimo (IBGE, 2010). Dessa forma, nos termos colocados pelo Ministério da Justiça, mais da metade dos cidadãos do Estado se mostravam como potenciais usuários da Defensoria Pública. Ainda assim, os Governadores do Estado, desde a promulgação da Constituição de 1988, limitou-se a proporcionar meios precários para garantir a representação judicial da população paranaense de baixa renda.

No Estado do Paraná, assim como em outros da Federação, a população economicamente carente era atendida pela Procuradoria de Assistência Judiciária, implementada na estrutura da Procuradoria-Geral do Estado, por meio de advogados públicos. Este arranjo não proporcionava a defesa completa dos interesses dos cidadãos, uma vez que não era de interesse do órgão, organizado para realizar a representação judicial do Estado, demandar contra o próprio Estado.

Outra forma, também utilizada em diversos outros Estados, era o convênio com a Ordem dos Advogados do Brasil (OAB). Advogados eram nomeados para realização de defesa dativa, que era subsidiada pelo Estado através do pagamento por precatórios. Esta forma se mostrava precária tanto para assistido, que dependia da boa vontade de um magistrado que lhe nomeasse defensor e de um advogado que aceitasse defendê-lo, quanto para advogado, que tinha seus honorários, fixados sempre no mínimo da tabela de honorários da $\mathrm{OAB}$ independentemente da complexidade do caso, pagos muito tempo após a atuação em virtude da demora no pagamento de precatórios.

Enfim, uma terceira forma consistia na assistência jurídica por núcleos das Faculdades de Direito do Estado. Uma vez que se apresenta no currículo da graduação em Direito a necessidade de prestação de estágio obrigatório, as faculdades forneciam, e permanecem fazendo, atendimento jurídico gratuito às pessoas sem condições de contratar advogado. Os estudantes, supervisionados por professores, atendem e dão encaminhamento às demandas apresentadas, fazendo defesas e pro- 
vocações perante o Poder Judiciário.

Assim como a atuação da Procuradoria de Assistência Judiciária, nas demais alternativas a petição contra o próprio Estado ficava prejudicada.

A demanda de criação da Defensoria era pauta constante dos movimentos sociais do Estado. Houve ainda alguma atuação do Ministério Público do Paraná nesta pauta, por meio de ações civis públicas.

Como estagiária de graduação em Direito pela primeira vez, me deparei com esta realidade em 2009 quando estagiava para a Fundação de Ação Social da Prefeitura de Curitiba na assistência jurídica gratuita de Direito de Família a pessoas carentes na Rua da Cidadania do Carmo, Regional Boqueirão sob a supervisão do Dr. Eduardo Luiz Calza, junto ao CRAS (Centro de Referência de Assistência Social). Prestávamos orientação jurídica com foco no Direito de Família, realizando entrevista, requisição de documentos e elaboração da petição inicial. Em seguida, o caso era encaminhado para a Defensoria Pública do Estado. No entanto, o atendimento era restrito aos residentes em Curitiba, uma vez que a Defensoria não possuía estrutura ou pessoal nem ao menos para o atendimento da capital do Estado, excluindo-se inclusive a região metropolitana.

Os advogados públicos que compunham a Procuradoria de Assistência Judiciária passaram a integrar a Defensoria do Estado criada pela Lei 55/91, mas a pouca estrutura impedia a atuação efetiva, estando longe de alcançar os termos da Constituição da República de 1988.

Ainda em 2009 acompanhei a iniciativa do Professor do Curso de Direito do Centro Universitário Curitiba, Dr. Eduardo Sanz que durante a Semana Acadêmica tentou lançar o movimento pró Defensoria Pública no âmbito da instituição com o evento denominado "Abertura do Movimento para a Instauração da Defensoria Pública do Paraná". Apesar da vontade de todos de que ocorresse a instauração do órgão, o Movimento desarticulou-se.

Em 2010, como dito, Pessuti encaminha o PL n ${ }^{\circ} 439 / 2010$ à ALEP. No ano seguinte, a retirada deste da pauta de votação aquece os ânimos dos movimentos sociais que haviam enxergado na atuação de Pessuti a possibilidade de regularização do órgão. Ainda assim, O cenário político era promissor, a ex-Procuradora Geral de Justiça, Dra. Maria Tereza Uille Gomes havia sido nomeada Secretária de Estado da Justiça e tinha entre as metas da Secretaria a implementação do órgão.

Neste cenário, Professores da Universidade Federal do Estado do Paraná (UFPR), sob a liderança da Professora Priscilla Placha Sá, convidam todos os interessados para uma reunião de articulação de onde nasce o movimento "Defensoria Já!", que congregava diversas entidades ${ }^{2}$ entorno de um único objeto: uma Defenso-

\footnotetext{
${ }^{2} \mathrm{O}$ movimento contou com grande participação de estudantes e professores, tendo ao lado do Diretório Acadêmico Clotário Portugal, entidade de representação dos acadêmicos de Direito do Centro Universitário Curitiba, o Centro Acadêmico Hugo Simas, do curso de Direito da UFPR, assim como o Centro Acadêmico de Ciências Sociais e os professores
} 
ria Pública paranaense livre, autônoma e independente.

Com a pressão social, a elaboração do Projeto de Lei foi conduzida pela Secretaria de Justiça, sob a coordenação do Dr. Miguel Gualano de Godoy, de maneira democrática, possibilitando a participação direta de representantes do movimento e da sociedade como um todo em reuniões, audiências públicas e consultas públicas online. Mesmo com toda a abertura dada, o projeto foi encaminhado à ALEP e aprovado em tempo recorde, sendo sancionado pelo Governador em 19 de maio de 2011, dia Nacional do Defensor Público. O resultado foi tido como a Lei Orgânica mais moderna e completa do país (GODOY, 2012, p. 23).

Conquistada a lei, faltava estruturar o órgão de fato. Em outubro de 2011, dez advogados do Estado que atuavam como Defensores Públicos, que optaram por permanecer na carreira, foram nomeados pelo Governador do Estado, na mesma cerimônia em que tomou posse a primeira Defensora Pública Geral do Estado do Paraná, Dra. Josiane Fruet Lupion (ANADEP, 2011).

A demora em dar início ao concurso para contratação de pessoal trouxe mais uma vez a atuação do movimento "Defensoria Já!". Somente em agosto de 2012 começaram as provas. Em março de 2013, 54 pessoas selecionadas no concurso foram nomeadas para apoio técnico e administrativo. Das 197 vagas para Defensor Público, 95 candidatos foram aprovados, conforme diário oficial de 16 de maio de 2013, mas até a presente data nenhum foi nomeado. Ou seja, outros 2 anos de espera para a população economicamente carente.

Ainda, há que se salientar outro parâmetro adotado pelo Ministério da Justiça, segundo o qual "a relação recomendável de Defensores Públicos por habitante deve oscilar na faixa aproximada de um defensor público para cada dez mil ou, no máximo, 15 mil que possam ser considerados alvo da Defensoria Pública" (IPEA; ANADEP, 2013). Nesse sentido, se levados em conta os 582 cargos para Defensor Público criados pelo artigo 244 da LC 136/2011, o Paraná fica acima da proporção mínima colocada pelo Ministério da Justiça, com 8.953 potenciais usuários por Defensor, levando em consideração os dados populacionais do Censo 2010.

Contudo, tendo em vista as únicas nomeações de Defensores Públicos, ocorridas em outubro de 2011, a Defensoria Pública do Paraná possui apenas 10 Defensores para atender todo o Estado.

daquela Instituição e do Diretório Central dos Estudantes da Universidade Estadual de Londrina. Se fizeram presentes ainda organizações não governamentais do Paraná como a Terra de Direitos e o Instituto de Defesa de Direitos Humanos (IDDEHA), e outras organizações da sociedade civil tais como a Comissão de Direitos Humanos de Londrina, a APP - Sindicato dos Trabalhadores em Educação Pública do Paraná, a Central Única dos Trabalhadores (CUT), o Movimento dos Trabalhadores Sem Terra (MST), o Sindicato dos Trabalhadores e Servidores Públicos Estaduais dos Serviços de Saúde e Previdência do Paraná (SindSaúde), o Programa PróJovem da Vila Torres, a Associação Nacional dos Defensores Públicos Estaduais (ANADEP), a Associação Nacional dos Defensores Públicos Federais (ANADEF), a Comissão de Direitos Humanos da Assembleia Legislativa do Paraná, dentre tantas outras que subscreveram o abaixo-assinado e manifestos publicados. 


\section{A demora na implementação da defensoria pública do Paraná como LIMITE DE REPRESENTAÇÃO POLÍTICA}

Retomando a noção de contrato social de Rousseau (1999), tem-se que, ao sair da condição primitiva por necessidade, o ser humano passa a viver em comunidade e, para tanto, se submete tacitamente ao pacto social que pode ser resumido em: "cada um de nós põe sua pessoa e poder sobre uma suprema direção da vontade geral e recebe ainda cada membro como parte indivisível do todo", produzindo um "corpo moral e coletivo" (ROUSSEAU, 1999, p. 36).

O autor traz assim a questão da "vontade geral" e a coloca como a única que pode reger as ações do Estado:

A primeira e mais importante consequência dos princípios acima estabelecidos é que somente a vontade geral pode por si só dirigir as forças do Estado, segundo o fim de sua instituição, que é o bem comum, porque se à oposição dos interesses particulares tornou necessário o estabelecimento de sociedades, a analogia desses mesmos interesses o fez possível. É o que há de comum nesses diferentes interesses que forma o laço social, e se não houvesse algum ponto em que todos os interesses estivessem de acordo, nenhuma cidade poderia existir (ROUSSEAU, 1999, p. 43).

O que fica é a dificuldade de determinar-se o conteúdo da "vontade geral" em uma sociedade complexa como a contemporânea. O autor limita-se a diferenciar vontade de todos, "soma das vontades particulares", de vontade geral, que "atende só ao interesse comum” (ROUSSEAU, 1999, p. 46). Marcus Abílio Pereira e Ernani Carvalho chegam a constar em sua análise que os diferentes interesses e percepções de mundo trazem "o conflito como componente inerente das relações políticas e sociais” (PEREIRA; CARVALHO, 2008, p. 55).

Para superar a dificuldade de estabelecimento da vontade geral, a Democracia representativa em sua noção hegemônica liberal, predominante na Democracia brasileira, traz normativas eleitorais que fixam procedimentos para a escolha de representantes políticos encarregados de expressar a vontade do povo. Isto significa dizer que, seguindo a concepção moderna de Democracia, entende-se esta forma de governo como organizadora dos procedimentos formais para legitimação dos representantes políticos.

A Democracia, portanto, é tida predominantemente como instrumento político-jurídico para a escolha de representantes políticos. Esse é o conceito trazido por Bobbio:

Afirmo preliminarmente que o único modo de se chegar a um acordo quan- 
do se fala de democracia, entendida como contraposta a todas as formas de governo autocrático, é o de considerá-la caracterizada por um conjunto de regras (primárias ou fundamentais) que estabelecem quem está autorizado a tomar decisões coletivas e com quais procedimentos (BOBBIO, 1986 apud PEREIRA, 2008, p. 50). acreditava

Junto a Bobbio está Joseph Schumpeter, que, segundo José Álvaro Moisés

que o 'método' democrático serve, essencialmente, para 'autorizar' governos através de eleições livres, mas não acreditava que os eleitores, ou seja, 'as pessoas comuns' fossem dotadas de suficiente autonomia e de capacidade de discernimento, para atribuir ou retirar legitimidade de qualquer regime político através de suas crenças (MOISÉS, 1995, p. 192).

Como consequência, para o autor as "pessoas comuns" devem ter sua participação política limitada ao voto: "uma vez tendo feito suas escolhas sobre a quem cabe governá-los, elas cessam qualquer outra função política e, até as próximas eleições, delegam as tarefas de produzir as políticas públicas adequadas" (MOISÉS, 1995, p. 193).

Para ambos os autores, a Democracia deve se limitar a garantir eleições periódicas livres, uma vez que a escolha do representante político por esses meios é suficiente para legitimá-lo. Este, por sua vez, deverá perseguir os interesses que entender cabíveis em cada momento.

Entretanto, entre os autores que se dedicam ao tema da Democracia na atualidade tem se entendido pela insuficiência da eleição para concessão de autorização ao representante político, bem como para controle de suas ações. Os motivos dessa corrente são claramente expostos por Bonavides:

Vista pelo divórcio consumado entre a vontade governada - a vontade passiva da cidadania - e a vontade governante, ou seja, a vontade da elite hegemônica, a representação não só perdeu o sentido da identidade (a ficção da paridade volitiva de governantes e governados), dantes postulada de maneira abstrata, mas peremptória, como reconheceu e instituiu de forma efetiva uma dualidade em que, unicamente, a sua esfera de soberania (a vontade privilegiada do representante) se impõe enquanto caudatária do egoísmo dos seus interesses, os quais logram, assim, eficácia, em dano óbvio da cidadania preterida, enfraquecida, menoscabada; a cidadania de que o representante é órgão.

Em face, pois, do malogro das formas representativas clássicas, o espírito democrático de nossa época se inclina para a rejeição do formalismo tra- 
dicional, em ordem a desterrar a supremacia liberal do poder, enquanto elemento institucionalizador de privilégios e desequilíbrios de classe (BONAVIDES, 2008, pp. 278-279).

Ou seja, para Bonavides a necessidade de se ir além do mero método para concessão da autorização para exercício do poder, que se dá de representado para representante, se justifica pelo flagrante abandono dos interesses dos cidadãos por parte daqueles que estariam imbuídos de persegui-los.

Antes de se aprofundar esta análise, há de se ressalvar que apesar de também se acreditar neste trabalho no divórcio entre a vontade de representantes e representados, se reconhece a Democracia representativa como um avanço dentre as formas anteriores de organização do Estado. A Democracia ressurge na modernidade como forma de disputa de poder e combate ao despotismo ( FIELD, 1959, p. 234). Nesse sentido coloca-se Boaventura de Souza Santos:

O capitalismo não é criticável por não ser democrático, mas por não ser suficientemente democrático. Sempre que o princípio do Estado e o princípio do mercado encontraram um modus vivendi na democracia representativa, esta significou uma conquista das classes trabalhadoras, mesmo que apresentada socialmente como uma concessão que lhes foi feita pelas classes dominantes. A democracia representativa é, pois, uma positividade e como tal deve ser apropriada pelo campo social da emancipação (SANTOS, 2005, p. 270).

Ainda assim, com intuito de buscar motivos para a não institucionalização, por meio de Lei Complementar, da Defensoria Pública no Estado do Paraná durante longos 23 anos, questionou-se aos entrevistados as razões que acreditavam ter determinado a promulgação da Lei apenas em 2011.

De maior relevância para a presente análise foi o apontamento a respeito da falta de intensa organização popular capaz de representar pressão perante os governantes (VENERI, 2013); a falta de orçamento suficiente para proporcionar uma Defensoria que alcance o Estado todo em igualdade com Ministério Público e Poder Judiciário (SOUZA FILHO, 2013); desinteresse dos governantes pelos direitos da população pobre (SÁ, 2013), podendo ser causada pelo temor em conceder poder a esta classe (SANTANA, 2013), ou mesmo pelo conhecimento de possíveis disputas judiciais entre Defensoria e Estado (VENERI, 2013).

Destaca-se outrossim que o motivo mais citado entre os entrevistados foi "falta de vontade política" (GODOY, 2013; SÁ, 2013; SANTANA, 2013; GOMES, 2013). Ou seja, para 4 dos 6 entrevistados a implementação da Defensoria Pública do Paraná esbarrava no desinteresse dos representantes políticos em conceder a população de baixa renda seu direito a Defensor Público que lhe permitisse o acesso à Justiça. 
Nessa esteira, Celso Fernandes Campilongo estuda os fatores que influenciam nas decisões dos representantes políticos. No início de sua obra admite que não se pode falar em congruência entre as vontades de governantes e governados, vez que "o processo representativo é farto em exemplos de que, mais do que as atitudes ou expectativas dos eleitores, outros fatores influem na conduta dos representantes. Dito de outro modo: a relação de representação não se exaure no processo eleitoral" (CAMPILONGO, 1988, p. 13).

Além da congruência, o autor se detém sobre as teorias acerca de input e output of demand, elitistas e policies decisions, mas acaba por concluir que nenhuma atitude ou interesse dos representados é capaz de assegurar a persecução de seus interesses, para Campilongo "é certo que elementos de outro nível - fundamentalmente de natureza econômica - desempenham função preponderante na definição de políticas públicas" (CAMPILONGO, 1988, p. 22).

Bernard Manin, Adam Przeworski e Susan C. Stokes, partindo do pressuposto de que os governados poderiam contar apenas com as eleições para controlar o desempenho de seus representantes, buscam compreender o que leva os políticos a atuarem de determinadas maneiras. Em primeiro lugar, admitem a possibilidade de um representante perseguir apenas interesses próprios, mas ressaltam que sua busca sempre será por recompensas. Assim, consideram que:

Os políticos tem preferências sobre as políticas públicas se a recompensa de manter-se no cargo ou a probabilidade de se reeleger depende das políticas por eles adotadas. Pode-se pensar em recompensa de manter-se no cargo em três formas: os políticos podem ter políticas favoritas e derivar utilidade de executá-las, podem querer realizar seus interesses pessoais, ou podem obter satisfação da honra de estar no cargo (MANIN; PRZEWORSKI; STOKES, 2006, p. 106).

Ainda apontam a relevância da satisfação dos financiadores, uma vez que para se eleger os políticos necessitam de verbas. Assim expõem que "os políticos podem vender aos grupos de interesse políticas que infligem um custo pequeno para cada eleitor - mas com benefícios concentrados nesses grupos de interesse -, e gastar nas eleições os recursos arrecadados em troca" (MANIN; PRZEWORSKI; STOKES, 2006, p. 113).

Pode se perceber uma congruência entre todos os autores trazidos no sentido de que determinados interesses são perseguidos pelos representantes quando estes tem como consequência benefícios para eles próprios ou para grupos com forte poder econômico, o que pode esclarecer as motivações para não implementação da Defensoria, visto que esta não se mostra como interesse de grupos de poder econômico. Ao contrário, seria capaz de instrumentalizar a população pobre e, com isso, afetar outros grupos com forte influência política, corroborando o trazido nas entre- 
vistas. Ademais, não se mostra como interesse próprio do representante, pois, como indicado pelos entrevistados, instrumentalizaria ações judiciais contra o próprio poder público.

Para além disto, se faz necessário apontar que a questão orçamentária, trazida por um dos entrevistados, pode ser tida como um fator fora do campo de análise dos eleitores que impediria a efetiva avaliação da qualidade das ações dos representantes. Tal questão aparece na teoria política como uma condicionante que barra a avaliação política condizente com as possibilidades. É o que se observa na seguinte passagem: "os eleitores não sabem tudo que precisariam saber, tanto para decidir prospectivamente o que os políticos deveriam fazer, quanto para julgar retrospectivamente se eles fizeram o que deveriam ter feito" (MANIN; PRZEWORSKI; STOKES, 2006, p. 106).

Dessa forma, a justificativa da falta de orçamento poderia ser a razão preponderante para o atraso na criação da Defensoria Pública do Paraná nos moldes constitucionais. Entretanto, como se passará a expor adiante, entende-se que a própria decisão orçamentária apresenta interesses conflitantes.

Foram apontados também o desconhecimento por parte dos próprios representantes políticos da necessidade e dever de implementar a Defensoria, bem como a falta de atuação consistente por parte do Ministério Público (GODOY, 2013), da Ordem dos Advogados do Brasil e do Tribunal de Justiça do Paraná (SÁ, 2013) e insensibilidade dos governantes (VENERI, 2013).

A segunda questão buscava compreender o papel da Defensoria Pública para a construção de um Estado de Direito, com intuito de aferir a relevância de sua institucionalização dentro do ordenamento jurídico. Para 4 dos 6 entrevistados, a existência de Defensoria representa um autêntico e legítimo Estado de Direito na medida em que possibilita o acesso à justiça para a população pobre (GOMES, 2013; VENERI, 2013), configurando-se como "instituição essencial ao funcionamento da justiça" (GODOY, 2013) e "como uma procuradora qualificada dos interesses dessa comunidade nas mais diversas áreas que um Estado de Direito precisa apresentar para se configurar como tal" (SÁ, 2013).

Para estes 4 entrevistados, a existência de Defensoria representa o Estado de Direito devido funções atribuídas a ela pela Constituição de 1988, que se traduz na persecução eminentemente jurídica de cada indivíduo que procura assistência do órgão, seja buscando efetivação de direitos individuais, seja garantia dos "direitos sociais de cidadania" para todos (SANTANA, 2013), como destacou outro entrevistado.

Atendo-se a isto, para outro entrevistado

a Defensoria não está lá só para defender um processo justo e adequado para os necessitados, mas para promover justiça, para reduzir as desigualdades, isso está no objetivo institucional da Defensoria - Lei Complemen- 
tar de 94, reformada pela 132 de 2009 -, está na Constituição. Ela é mais do que uma instituição promotora do estado de Direito, ela é promotora do Estado Democrático de Direito e a falta dela, com certeza absoluta, deslegitima um Estado Democrático de Direito (SÁ, 2013).

Portanto, para este entrevistado a relevância da Defensoria está na atuação pela busca da justiça social, pela melhor distribuição dos recursos patrimoniais, culturais e de poder, afim de caminhar no sentido da concretização do Estado Democrático de Direito.

Em contraposição, outro entrevistado destacou que, tendo em vista a atuação predominante da Defensoria na defesa de direitos individuais, sua implementação não simboliza o Estado de Direito, acreditando que para se alcançar efetivamente tal ideal são necessárias reformas no Poder Judiciário e no Ministério Público.

Quando nós temos hoje no Brasil um sistema judiciário que não é democrático, um sistema de Ministério Público que também não é democrático, e que tem uma atuação extremamente forte nas decisões e que decide, praticamente sempre, na criminalização dos movimentos sociais, não adianta ter uma Defensoria Pública. Não é que não adianta para nada, não adianta especificamente para o fortalecimento ou não do Estado Democrático de Direito (SOUZA FILHO, 2013).

Há que se colocar que a posição defendida pelos dois últimos entrevistados citados coincidem, apesar de parecerem contraditórias. Ambos acreditam que a Defensoria representa um Estado de Direito na medida em que se dispõe a buscar a concretização dos valores democráticos e da igualdade material. Há que se ressaltar que a atuação em casos individuais também possibilita mudanças para a coletividade, principalmente quando a Defensoria provoca o Supremo Tribunal Federal em casos de repercussão geral. Ainda assim, admitindo que a Defensoria tende a se limitar à tutela dos direitos individuais, defende-se aqui também sua atuação em conjunto com movimentos sociais.

A terceira pergunta, por sua vez, tinha por intuito saber se os entrevistados concordavam, e em qual medida, com a proposição exposta neste trabalho de que a falta de Defensoria Pública no Paraná demonstrava uma falha na representação política. Apenas um dos entrevistados afirmou que não acreditava que a representação política poderia ser medida desta forma. Pode-se compreender de seu posicionamento que a justificativa de falta de orçamento suficiente, em sua opinião, é plausível: "Então a estrutura da Defensoria Pública é uma estrutura tão cara quanto à do Ministério Público e do Poder Judiciário [...] E isso, no longo prazo, acaba inviabilizando o Estado" (SOUZA FILHO, 2013). Ou seja, sua ausência pode parecer uma falha para aqueles que não enxergam determinantes aparentes apenas para aqueles que conhecem o interior da administração pública. 
Com a devida licença, há que se contrapor a isto, posto que a destinação de orçamento é também uma decisão política. O artigo $134, \S 2^{\circ}$ da Constituição da República determina que a Defensoria tem iniciativa de sua proposta orçamentária. Esta proposta, conforme artigo $8^{\circ}$ da Lei Complementar Estadual 136/11, deverá passar tanto pelo Executivo, quanto Legislativo para ser consolidada. Neste momento se expressa o interesse político e, como se verá abaixo, este dá preferência para o exercício das funções públicas de julgar e acusar, optando por não viabilizar a defesa.

O III Diagnóstico Defensoria Pública no Brasil (Ministério da Justiça, 2009, p. 86) traz a média do orçamento destinado ao Poder Judiciário, ao Ministério Público e à Defensoria em todo o Brasil:

Com relação ao orçamento executado pelo Poder Judiciário, Ministério Público e Defensoria Pública das unidades da Federação no que diz respeito ao orçamento total do estado, observou-se que em média o Poder Judiciário dos Estados absorve 5,34\% dos gastos totais do estado, enquanto que o orçamento do Ministério Público foi de $2,02 \%$ do orçamento do Estado e o da Defensoria Pública foi em média de $0,40 \%$ do total de gastos pelas unidades da Federação.

Mais uma vez se observa a pouca importância dada à defesa e orientação jurídica às pessoas em situação de vulnerabilidade econômica. Disto deriva a diferença de alcance destas instituições em todo o Brasil. O Mapa da Defensoria Pública no Brasil, elaborado pela Associação Nacional dos Defensores Públicos - ANADEP, em parceria com o Instituto de Pesquisa Econômica e Aplicada - IPEA, publicado em 13 de maio de 2013, traz uma comparação entre o número de Defensores, de membros do Ministério Público e de Magistrados estaduais em todo o Brasil. Se referindo a todas as Comarcas brasileiras, aponta que:

Na maioria delas (72\%), contudo, a população conta apenas com o estadojuiz, o estado-acusação/fiscal da lei, mas não conta com o estado-defensor, que promove a defesa dos interesses jurídicos da grande maioria da população, que não pode contratar um advogado particular (IPEA; ANDEP, 2013).

Ou seja, pouco mais de um quarto das Comarcas brasileiras contam com um sistema de justiça em sua completude, que funcione com um magistrado julgador, um membro do Ministério Público acusador e fiscal da lei, e com a garantia de defesa por instituição autônoma e permanente para aqueles que não têm condições de contratar advogado. A prioridade, portanto, se mostra em acusar e julgar, mas não em defender.

Os demais entrevistados concordam com a falta de representatividade po- 
pular nas decisões políticas. O maior destaque se dá para o apontamento feito por uma das entrevistadas que aponta que a ausência de Defensoria se deve em razão da política elitista paranaense e do desinteresse dos grupos dominantes em concretizar este direito (SÁ, 2013). Mostra-se imprescindível neste ponto atenção às teorias elitistas e pluralistas que analisam o fenômeno de participação política, bem como as críticas feitas a elas.

Primeiramente, partindo do mesmo pressuposto de Robert Dahl, entende-se "que uma característica-chave da democracia é a contínua responsividade do governo às preferências de seus cidadãos, considerados como politicamente iguais" (DAHL, 2012, p. 25). Assim, a Democracia deve garantir que os interesses dos cidadãos estejam representados nas decisões políticas.

Porém, quando Dahl evolui do dever ser da Democracia, para a análise de seu real desenvolvimento, passa a considerar que apenas algumas minorias exercitam efetivamente o poder político, garantindo a persecução de seus interesses. $\mathrm{O}$ autor é adepto da teoria do elitismo democrático, ou pluralismo elitista, a qual possui como traço essencial

a crença de que é possível aceitar a tese fundamental do elitismo clássico, segundo a qual são as minorias que comandam a vida política, e conjugá-la com a defesa da democracia, desde que esse sistema político seja entendido de uma maneira específica (PERISSINOTO, 2009, p. 129).

Para o autor é possível defender a Democracia, admitindo a existência de elites, desde que se compreenda que a Democracia se resume a "um regime de eleições livres e competitivas, no qual diversas elites competem entre si para conquistar o voto dos governados" (PERISSINOTO, 2009, p. 131), retomando o conceito de Joseph Schumpeter. A competição entre as elites seria satisfatória para a conquista da Democracia, uma vez que elites autônomas entre si e perante o Estado podem competir pelo poder político, evitando o despotismo. Ademais, em oposição ao que se pretende defender neste trabalho, para esta corrente

a maior ameaça à democracia não vem das elites, mas, ao contrário, da presença das massas na política. Há, entre os pluralistas, um grande temor em relação ao que avaliam ser o caráter autoritário do homem "médio". Por essa razão, avaliam ser melhor para a continuidade da democracia a existência de certa apatia da imensa maioria do que seu engajamento direto na vida política (PERISSINOTO, 2009, pp. 129-130).

Esta teoria, assim como as de Schumpeter e Bobbio, embasam a noção liberal de Democracia e justificam a falta de abertura de espaços de participação direta. Dentre as críticas a elas, destaca-se o exposto por Campilongo: 
as demandas políticas são mesmo formuladas por um pequeno número de agentes. Porém, há que se registrar que esse realismo está circunscrito ao contexto de sociedades marcadas pela concentração do capital nas mãos da minoria, pela desigualdade de oportunidades sociais e políticas e pela redução do cidadão ao papel de simples consumidor dos produtos políticos. Enfim, esse realismo não se mostra interessado em avaliar as razões da apatia e incapacidade dos eleitores diante das questões políticas nem examina por que os sistemas partidários são de escassa representatividade. O argumento da "apatia das massas" [...] não verifica que um sistema político que prima pelo disfarce das questões e pela ausência de responsabilidade dos representantes para com os representados desestimula a participação popular. A apatia dos eleitores chega a ser vista como benéfica à estabilidade política, e, por isso, é discretamente estimulada pelo sistema. Além disso, as demandas das classes socioeconômicas dotadas de maior capacidade de agregação de interesses, organização e conflito são sempre mais efetivas - o que deságua na apatia dos setores circunstancialmente privados dessa capacidade. O "realismo" dessas posturas repousa na hipótese inverificável de que as capacidades políticas de pessoa mediana numa sociedade de mercado são um dado fixado, ou, pelo menos, com pouca probabilidade de mudar em nossa época (CAMPILONGO, 1988, pp. 2021).

À vista disso, pode se compreender que o autor assume a existência de elites políticas que dominam os demais, impondo seus interesses. De outra feita, questiona esta teoria como realidade intrínseca e imutável, apontando sua falha em não levar em consideração a conjuntura que leva à apatia das massas. Ou seja, Campilongo não apenas não acredita que as massas devam ser deixadas de fora, mas percebe que seus interesses não estão na pauta política e que isto desestimula sua participação. Considera o autor, ademais, as consequências dessa "apatia" no ordenamento jurídico, quando afirma que "sendo as instituições representativas os mecanismos do sistema político mais vinculados à produção de lei, é natural que a crise da representação tenha reflexos no ordenamento jurídico" (CAMPILONGO, 1988, p. 55).

Ainda sobre as desigualdades de participação no processo democrático, tem-se marcante construção do escrito argentino Atilio A. Boron que afirma a desigualdade social como limitador da Democracia

quando os pobres se transformam em indigentes e os ricos em magnatas, sucumbem a liberdade e a democracia. A primeira não pode sobreviver ali onde uns estejam dispostos a vendê-la "por um prato de lentilhas" e outros disponham da riqueza suficiente para comprá-la a seu bel-prazer (BORON, 2002, p. 13). 
Mais além, indicaram os entrevistados que a demora na implementação da Defensoria pode decorrer da política predominantemente clientelista em que o governante proporciona o exercício de direitos como se fossem favores de forma a conquistar crédito perante a sociedade (VENERI, 2103); falta de vontade política e limites da judicialização de políticas públicas ${ }^{3}$; falha pessoal dos representantes políticos, limitações da representação e de sua estrutura que não prevê formas suplementares para a produção da normativa necessária (GODOY, 2013).

A respeito dos favores políticos é necessário trazer um apontamento de Campilongo. Um dos entrevistados colocou que uma das facetas da política que se expunham na ausência de Defensoria Pública é a prática do clientelismo. Campilongo, reconhecendo a falibilidade da representação política, questiona de que forma os procedimentos eleitorais se mantém e os políticos continuam sendo eleitos. Para o autor uma das formas de garantir continuidade do atual sistema que se encontra altamente incorporada na sociedade é o clientelismo e "toda sorte de favores, benesses e tráfico de influências captados em benefício de indivíduos ou grupos particulares" (CAMPILONGO, 1988, pp. 36-37).

A quarta pergunta visa informações acerca de outra característica da Democracia liberal. Em vistas da compreensão de Democracia como procedimento eleitoral para autorização do governante, o acesso a foros de representação (mandatos, coalizões, conselhos, espaços públicos de manifestação) se mostra limitado. $\mathrm{O}$ que se pretendia era saber quanto essas limitações afetam o exercício dos direitos fundamentais, pressupondo a Defensoria como parte destes.

Um dos entrevistados, com intensa atuação em movimentos sociais, relatou experiências em que manifestações na Câmara Municipal de Londrina foram dificultadas ${ }^{4}$, demonstrando a crença dos representantes políticos de que, uma vez eleitos para seus cargos, não necessitam mais conhecer as vontades do povo. A Democracia em sua plenitude exige a inclusividade por meio da participação e a liberalização pela contestação pública. É o que traz Dahl (2012, p. 31) em Poliarquia.

Neste ponto, todos os entrevistados concordam que o limite de acesso prejudica o exercício de direitos fundamentais na medida que: limitam as garantias

\footnotetext{
3 "Por mais que a Defensoria, por parte da população, tivesse sido reivindicada, foi alvo de várias ações civis por parte do Ministério Público, essas ações acabavam não tendo êxito, porque no Poder Judiciário ainda tem uma discussão muito séria sobre os limites de discricionariedade do gestor - no caso, limite de discricionariedade do Poder Executivo ou do Governador - que é a questão da judicialização das políticas públicas. Limites de judicialização de políticas públicas”. GOMES, 2013.

4 "Na Câmara de Vereadores de Londrina, às vezes, você é impedido de ir com uma faixa. A faixa cobrando a Defensoria Pública eles impediram a gente de colocar. Eu disse: 'Eu vou colocar porque é um direito.' E aí eu fui com o Defensor Geral lá de Londrina - Dr. Clayton - e falei: 'O Senhor vai ler a Constituição para eles'. Acabamos fazendo uma fala na Câmara Municipal. Ele leu e falou: 'Não pode. Ele vai colocar'. Nós precisamos ter o Defensor lá para isso". SANTANA, 2013.
} 
constitucionais e trazem a impossibilidade de apresentação de demandas por pessoas e movimentos sociais (VENERI, 2013); impedem o acesso aos direitos sociais (GOMES, 2013); os direitos coletivos não conseguem ser efetivamente tutelados pelo judiciário e dependem da cobrança direta aos responsáveis e os movimentos sociais são criminalizados quando na busca pelo reconhecimento de suas demandas (SOUZA FILHO, 2013).

Ainda levantou-se fatores relativos aos Conselhos, como os vícios de representatividade internos e nas disputas eleitorais, o não reconhecimento de seu poder normativo, a estrutura, gestão e orçamento a ele destinado, bem como o despreparo observado nos conselheiros e a desorganização da sociedade civil, na afirmação de que

mesmo os conselhos às vezes não tem maturidade também para compreender não apenas a importância dos Conselhos Estaduais, mas dos Conselhos Municipais, da criação dos fundos, do manejo dos recursos públicos, do controle do orçamento público, discussões de orçamento participativo, como controlar a execução do orçamento. Todo esse contexto de participação popular que se dá através dos conselhos e de diversas outras formas, quando a sociedade não está bem organizada, não se movimenta adequadamente no sentido da construção de políticas públicas, então a gente percebe essa situação (GOMES, 2013).

Portanto, mesmo a abertura existente no Executivo, muitas vezes se mostra sem estrutura adequada da situação de modo a tornar aquela instância capaz de agir em sua plenitude. Ressalta-se, por outro lado, a total ausência de instâncias de participação popular no Legislativo.

Isso inexiste no Poder Legislativo. Esse é um desiquilíbrio que é muito fácil de a gente ver. Como a gente exerce controle popular sobre o mandato legislativo? A gente não tem esse controle hoje. A gente não tem nenhuma forma de participação popular obrigatória no mandato legislativo. O poder executivo é obrigado a nomear pessoas para o conselho - o Conselho dos Direitos da Mulher, das Pessoas com Deficiência, do Idoso, Conselho dos Direitos Humanos. A gente não tem um conselho dentro do Poder Legislativo. A gente tem as Comissões, essas Comissões não são abertas ao povo. Em geral, ao contrário, a maioria das Comissões são fechadas. Algumas comissões são abertas. Qualquer pessoa pode ter acesso a elas, escutar as reuniões, solicitar as atas. Mas não permitidas as intervenções populares. [...] Ao contrário, no Poder Legislativo depende da liberalidade do legislador. Se um deputado quiser, ele faz a solicitação de uma audiência pública, se ele quiser, ele promove a divulgação de uma determinada reunião de 
uma comissão. Isso, portanto, fica ao critério de escolha do parlamentar, quando muito. Quando ele não tem que submeter esse pedido ao plenário, à mesa diretiva da Assembleia. Isso é muito ruim (GODOY, 2013).

Fica, pois, óbvia a falta de participação da população no processo legislativo de maneira obrigatória, diferente do que ocorre com a institucionalização, por meio de Lei ou Decreto, de instâncias de participação popular no âmbito do Executivo.

Uma das entrevistadas trouxe outra contribuição ressaltando que "nós, infelizmente, vivemos em um país em que talvez nós não tenhamos consciência das possibilidades de representação" (SÁ, 2013). De sua fala retira-se a falta de conhecimento por parte da população de seus direitos e dos espaços onde reivindicá-los.

Relatando sobre a experiência tida com a reação das pessoas quando, pelo movimento Defensoria Já foi realizada panfletagem para conscientizar a população acerca de seu direito a Defensoria Pública, Afirmou: "A gente via que isso não fazia questão para as pessoas, e, no limite, se não faz questão para quem vota, talvez o Governo [...] também não vai se movimentar" (SÁ, 2013). Enfim, ela salienta que

acho que é a cobra que gira em torno do próprio rabo: eu não demando, o governo não identifica o interesse, ele não faz e eu continuo inerte, como eu não tenho escola, eu não me aproprio do conhecimento, não me emancipo e... vida de gado (SÁ, 2013).

A respeito disso é importante destacar a informação qualificada como um dos pressupostos da Democracia. Apenas pelo conhecimento trazido através da informação para todos é que se pode concretizar a igualdade na participação política e, portanto, a existência de Democracia. Entendimento este corroborado por Fernando Whitaker da Cunha no seguinte trecho:

Temos eleição, mas não possuímos representação, pelo fato dessa última não refletir, efetivamente, a consciência política do povo, pela fragilidade do binômio votante-votado, num meio inculto e despreparado, para o necessário diálogo entre cidadão e o candidato, que combata as oligarquias, mas que estimule a criação de classes dirigentes desenvolvimentistas, das "elites funcionais" (Hélio Jaguaribe), devidamente preparadas, no povo politizado. "Educar é Governar" já observava o prodigioso Rodolfo Rivarola (CUNHA, 1981, p. 48).

Por fim, acerca da capacidade da Defensoria de garantir direitos fundamentais apontaram os entrevistados que ela seria capaz tendo em vista que defende os mais pobres dos pobres, esquecidos por juristas e pelos poderes constituídos (VE- 
NERI, 2013); bem como por incluir os 98\% dos presos do Estado que não possuem condições de contratar advogados.

Em contrapartida, um dos entrevistados ressaltou que a Defensoria sozinha não é capaz de alterar o quadro de desrespeito aos direitos fundamentais, isto só será possível, em sua opinião, por meio de mobilizações populares que busquem a qualificação da justiça e a verdadeira democracia (SANTANA, 2013).

Outros dois entrevistados condicionam a superação dos limites no exercício dos direitos fundamentais à compreensão pela Defensoria de uma função específica. De acordo com um deles:

Eu vejo a Defensoria sempre como a grande articuladora dos direitos individuais. Ela pode atuar nos direitos coletivos, ela tem competência para fazer isso, mas depende muito da vontade estrutural do órgão; e, mais ainda, do defensor. [...] Então, no fundo a Defensoria acaba sendo uma ponte de chegada da cidadania nas esferas judiciais. Sem garantir que as esferas judiciais funcionem efetivamente - porque elas podem dar decisões contrárias - e sem que esse acesso chegue em última instância a resolver o problema. [...] Então o sistema judicial brasileiro não comporta muito bem, não é feito para resolver os problemas dos pobres. Ele é feito para resolver os problemas dos ricos. Ele é estruturalmente para as classes dominantes. Então a Defensoria é um paliativo, mas ainda não é uma solução. A solução, a meu ver, passa além da criação de uma Defensoria, da reestruturação do sistema judiciário como um todo, e a reestruturação do Ministério Público, obviamente (SOUZA FILHO, 2013).

Para este entrevistado, portanto, a Defensoria só será capaz de alterar a realidade de coisas se o Judiciário e o Ministério Público forem repensados para incluir também em suas atuações os interesses das camadas socialmente excluídas, acima de tudo, se a Defensoria atuar na defesa dos interesses coletivos. Seu posicionamento se baseia na interessante compreensão de que as demandas que exigem reparação de violação perpetrada pelo Estado e a exigência de respeito a direito individual não produzem a alteração nas atividades reiteradas de desrespeito a coletividade. Somente pela demanda coletiva, poderia a Defensoria ser considerada como um avanço para o alcance do Estado Democrático.

Enfim, outro posicionamento parte do pressuposto de que a Defensoria Pública compreende seu papel enquanto defensora dos direitos coletivos em conjunto com movimentos sociais e que, dessa forma, sua atuação evidenciará ainda mais a crise da representação política.

Mais do que isto, este entrevistado, que atuou intensamente nos procedimentos participativos da elaboração do anteprojeto de lei, aponta que a população pode participar das decisões políticas. 
Então a Defensoria Pública é uma prova viva de que é possível você estabelecer uma política pública de forma ampla, plural, democrática, com participação popular, com participação daquele potencialmente afetados por aquela política, que, no caso, era a criação da Defensoria.[...] Por isso, cai por terra esse argumento elitista de que pessoas pobres, sem instrução não podem participar da vida pública, da criação de políticas públicas, por mais técnicas que elas sejam, como é criação, a estruturação de um órgão como a Defensoria Pública (GODOY, 2013).

Ou seja, para ele o próprio processo de criação da Lei Orgânica da Defensoria demonstra que é possível se fazer política pública com participação popular, inclusive daqueles potencialmente atingidos, vez que todos tem condições de contribuir para a construção do Estado. Relata a contribuição que diversas mulheres presentes em uma audiência pública tiveram para a identificação de uma demanda reprimida, que se apresentava como verdadeiro gargalo do sistema judiciário: a necessidade de criação de um Núcleo para realização de investigação de paternidade.

\section{Conclusão}

Apoiando-se nos teóricos políticos apresentados e nas entrevistas realizadas, percebeu-se o consenso quanto a existência de falha de representação dos interesses dos governados pelos governantes, mormente dos interesses da população de baixa renda, confirmando a afirmação primeira trazida no presente trabalho.

Nessa esteira, a demora na implementação da Defensoria Pública do Paraná se deve, pelo que se pode extrair do exposto, à busca dos representantes políticos em alcançar vantagens para eles próprios ou aos grupos que os financiam. A ausência do órgão ainda se mostra como interesse privado não apenas dos representantes políticos, como dos demais órgãos envolvidos no sistema de justiça, conforme trazido em uma das entrevistas que apontou a pouca intervenção por parte do Poder Judiciário, do Ministério Público e da Ordem dos Advogados do Brasil neste processo.

Ressalta-se a contribuição de um dos entrevistados no sentido de que o desconhecimento por parte tanto de representantes, como de representados da necessidade de criação da Defensoria Pública teria influenciado tão longa espera. Uma das entrevistadas corrobora esta afirmação colocando que a população, desconhecendo seus direitos, não se mobiliza e, assim, não cobra daquele representante, eleito por meio de seu voto, a institucionalização de tal órgão essencial ao exercício da cidadania. Nessa mesma medida, investir na Defensoria não aparece para o governante como possível fonte de capital político, prolongando o descumprimento do mandamento constitucional.

Tem-se aqui a imprescindibilidade da informação e educação de qualidade para a existência de uma Democracia real, como descrito por Cunha e Dahl. 
A questão mais relevante dentre todas, para esta análise, está na compreensão exposta por Campilongo que, reconhecendo as noções elitistas e pluralistas da política, enfatiza que a detenção do poder político por uma minoria não pode ser entendida como fato imutável, mas como decorrente da imensa desigualdade social e do reiterado atendimento aos interesses daqueles com maior poder econômico, em detrimento do restante da sociedade.

Campilongo aponta que as teorias pluralistas e elitistas se furtam à análise das razões por detrás da apatia das massas. Estas teorias inclusive exaltam a apatia como necessária para o melhor funcionamento do sistema político. Entretanto, para o autor, é exatamente a falta de persecução dos interesses da população de baixa renda, em especial, que desestimula a participação deste segmento nas decisões políticas. Afora isto, coloca que a desigualdade de poder é característica das Democracias em sociedades marcadas pela intensa desigualdade social.

Por fim, destaca-se que a dificuldade de acesso aos espaços de tomada de decisão impede a cobrança por parte daqueles conscientes de seus direitos. A Democracia predominantemente indireta deixa o cidadão à mercê da vontade de seu representante político, não lhe sendo permitida a intervenção direta nas construções de interesse coletivo.

Conclui-se, portanto, pela necessidade de abertura da Democracia, complementando-se a representação com a participação direta do povo, consagrando o princípio basilar de todo o ordenamento jurídico criado pela Constituição da República de 1988, qual seja a soberania popular. Fica a missão de construir formas de compartilhar o poder normativo e viabilizar maneiras para o exercício e fortalecimento do controle social de mandatos políticos no Legislativo e Executivo.

\section{REFERÊNCIAS}

ANADEP. Governador do Paraná dá posse aos 10 primeiros Defensores Públicos. DF: 2011. Disponível em: http://www.anadep.org.br/wtk/pagina/materia?id=12793. Acessado em: 13.04.2013.

BONAVIDES, Paulo. Teoria Constitucional da Democracia Participativa (por um Direito Constitucional de luta e resistência; por uma Nova Hermenêutica; por uma repolitização da legitimidade). 3. ed. São Paulo: Malheiros, 2008.

BORON, Atilio A. Estado, Capitalismo e Democracia na América Latina. Tradução de Emir Sader. 2. ed. São Paulo: Paz e Terra, 2002.

CAMPILONGO, Celso Fernandes. Representação política. São Paulo: Ática, 1988. CUNHA, Fernando Whitaker da. Representação política e poder. 2. ed. Rio de Janeiro: Freitas Bastos, 1981.

DAHL, Robert A. Poliarquia: Participação e Oposição. Tradução de Celso Mauro 
Paciornik. 1. ed. 2. reimpr. São paulo: Editora da Universidade de São Paulo, 2012.

FIELD, G. C. Teoria Política. Rio de Laneiro: Zahar Editôres, 1959.

GODOY, Miguel Gualano de. Entrevista concedida a Ana Zaiczuk Raggio. Curitiba, 21 mar. 2013.

- Lei orgânica da Defensoria Pública do Estado do Paraná anotada: lei complementar estadual 136, de 19 de maio de 2011. Curitiba: Juruá, 2012.

IBGE. Censo 2010. 2010. Disponível em: http://www.ibge.gov.br/home/estatistica/ populacao/censo2010/caracteristicas_da_populacao/caracteristicas_da_populacao_ tab_pdf.shtm. Acessado em: 13.04.2013.

IPEA. ANADEP. Mapa da Defensoria no Brasil. Brasília: 2013. Disponível em: http://www.ipea. gov.br/sites/mapadefensoria/defensoresnosestados. Acessado em: 30.04.2013.

MANIN, Bernard; PRZEWORSKI, Adam; STOKES, Susan C. Eleições e representação. Lua Nova, São Paulo, n. 67, pp. 105-138, 2006.

MIOSÉS, José Álvaro. Os brasileiros e a democracia - bases sócio-políticas da legitimidade democrática. São Paulo: Ática, 1995.

PEREIRA, Marcus Abílio; CARVALHO, Ernani. Boaventura de Sousa Santos: por uma nova gramática do político e do social. Lua Nova, São Paulo, n 73, p. 45-58, 2008.

PERISSINOTO, Renato. As elites políticas: questões de teoria e método. Curitiba: Ibpex, 2009.

ROUSSEAU, Jena-Jacques. O Contrato Social: princípios de direito político. Tradução de Antônio P. Machado. 19. ed. Rio de Janeiro: Ediouro, 1999.

SÁ, Priscilla Placha. Entrevista concedida a Ana Zaiczuk Raggio. Curitiba, 20 mar. 2013.

SANTANA. Carlos Enrique. Entrevista concedida a Ana Zaiczuk Raggio. Curitiba, 1 abr. 2013.

SANTOS, Boaventura de Sousa. Pela mão de Alice - o social e o político na pósmodernidade. 10. ed. São Paulo: Cortez, 2005.

SOUZA FILHO, Carlos Frederico Marés de. Entrevista concedida a Ana Zaiczuk Raggio. Curitiba, 25 mar. 2013.

VENERI. Tadeu. Entrevista concedida a Ana Zaiczuk Raggio. Curitiba, 27 mar. 2013. 